\title{
Manifestations and Related Risk Factors of Thrombocyte Abnormalities in HIV-Positive Patients Before and After the Initiation of ART
}

\author{
Bei $\mathrm{Li}^{\prime}$ \\ Leidan Zhang ${ }^{2}$ \\ Ying Liu' \\ Jing $\mathrm{Xiao}^{2}$ \\ Xinyue Wang ${ }^{2}$ \\ Yuqing $\mathrm{Wei}^{1}$ \\ Lina Fan $^{3}$ \\ Yujiao Duan' \\ Guoli $\mathrm{Li}^{4}$ \\ Yaxian Kong ${ }^{4}$ \\ Hongxin Zhao (D) \\ 'Clinical and Research Center of \\ Infectious Diseases, Beijing Ditan \\ Hospital, Capital Medical University, \\ Beijing, People's Republic of China; \\ ${ }^{2}$ Department of Infection, Beijing Ditan \\ Hospital, Peking University, Beijing, \\ People's Republic of China; ${ }^{3}$ Department \\ of Infectious Disease, The Tianjin Second \\ People's Hospital, Tianjin, People's \\ Republic of China; ${ }^{4}$ Institute of Infectious \\ Diseases, Beijing Ditan Hospital, Capital \\ Medical University, Beijing, People's \\ Republic of China
}

Background: At present, the thrombocyte abnormality is not well described before and after the initiation of antiretroviral therapy (ART). The purpose of this research is to investigate the dynamic changes and related risk factors of thrombocytopenia and thrombocytosis in HIV-infected individuals.

Methods: We performed a real-world observational study among 6637 HIV patients who started ART from January, 2013 to August, 2020 at the Beijing Ditan Hospital. Hazard indicators linked with thrombocytopenia and thrombocytosis were analyzed by logistic/Cox regression.

Results: The prevalence of thrombocytopenia and thrombocytosis was $2.65 \%$ and $5.85 \%$ among ART-naïve patients, respectively. Correlated risk factors: (thrombocytopenia) older age, coinfection with $\mathrm{HBV}$, leucopenia, anemia, and CD4 count $<350$ cells/uL; (thrombocytosis) $\mathrm{WBC}$ level $\geq 4.0 \times 10^{9} / \mathrm{L}$, anemia, NLR $\geq 2.0$, and CD4 count $\geq 350$ cells $/ \mathrm{uL}$. As for the recovery rate, it was $86.6 / 54.2,83.4 / 46.3,66.0 / 35.1$, and $65.3 / 33.9$ per $100 \mathrm{PYFU}$ in thrombocytopenia/thrombocytosis at different treatment period $(12 \mathrm{~m}, 24 \mathrm{~m}, 36 \mathrm{~m}$, and $48 \mathrm{~m})$. While the new-onset incidence of thrombocytopenia/thrombocytosis at different ART period (12m, 24m, 36m, 48m, 60m, 72m, and 84m) was 0.25/7.2, 0.19/6.31,0.16/4.74, 0.16/4.55, $0.16 / 4.48,0.15 / 4.41$, and $0.15 / 4.39$. And the driving forces of thrombocytosis were antiretroviral treatment, female, overweight, and WBC level $\geq 4.0 \times 10^{9} / \mathrm{L}$.

Conclusion: In the medical practice, while paying attention to thrombocytopenia, clinicians should be highly vigilant about the thrombocytosis of HIV/AIDS patients, and related treatment strategies need to be further studied.

Keywords: thrombocyte abnormalities, thrombocytopenia, thrombocytosis, HIV, antiretroviral therapy

\section{Introduction}

Thrombocytes, derived from megakaryocyte cytoplasm, play a critical role in haemostasis, thrombosis and coagulation of blood. ${ }^{1}$ The normal platelet count ranges from 100,000 to $300,000 / \mu \mathrm{L}$ in adults. During human immunodeficiency virus (HIV) infection, low or high platelets concentration is coupled with the incidence of both acquired immunodeficiency syndrome (AIDS) and non-AIDS-defining events. ${ }^{2}$

Hematologic abnormalities are common manifestations of advanced HIV dis-

Correspondence: Hongxin Zhao Clinical and Research Center of Infectious Diseases, Beijing Ditan Hospital, Capital Medical University, No. 8 Jing Shun East Street, Beijing, 100015, People's Republic of China

Email Drzhao66@ccmu.edu.cn

\section{ease and AIDS.}

Unfortunately, the available information on thrombocytopenia and thrombocytosis is limited for HIV-positive individuals in China. Therefore, in this study, we systematically investigated the dynamic changes of thrombocytopenia and 
thrombocytosis before and after ART, and further analyzed the associated risk indicators, so as to provide certain guidance and basis for the optimization of clinical treatment strategies.

\section{Materials and Methods Study Participants}

We performed a retrospective cohort study on 6637 HIVinfected members who initiated ART at the Beijing Ditan Hospital from January, 2013 to August, 2020. Subjects were excluded (1) if their age was $<18$ years while ART was introduced, (2) pregnant women, and (3) those with incomplete baseline data. To investigate the rate of newonset thrombocyte abnormalities, 6074 HIV-positive individuals who were visited at least once (apart $\geq 12$ months) after the beginning of therapy were conducted.

The protocols were approved by the ethics committees of Beijing Ditan Hospital, Capital Medical University (Approval No. 2021-022-1), and were carried out by the Declaration of Helsinki. All of clinical and laboratory data were used anonymously, so written informed consent was not required.

\section{Definitions}

Conditions were defined based on the following parameters in peripheral blood. Thrombocytopenia: platelet (PLT) count $<100 \times 10^{9} / \mathrm{L}$; thrombocytosis: platelet count $>300 \times 10^{9} / \mathrm{L}$; leucopenia: white blood cell (WBC) level $<$ $4.0 \times 10^{9} / \mathrm{L}$; anemia: hemoglobin (HGB) level $<110 \mathrm{~g} / \mathrm{L}$ (female) or $<120 \mathrm{~g} / \mathrm{L}$ (male). Hematological recovery after ART was delimited as states that the PLT counts would be within the reference range of (100-300) x $10^{9} / \mathrm{L}$.

\section{Data Collection}

The following demographic, clinical and laboratory data were extracted from the electronic medical record system: age, sex, HIV transmission route, WHO clinical stage, body mass index (BMI), hepatitis B virus (HBV), hepatitis $\mathrm{C}$ virus (HCV) serostatus, syphilis, HIV viral load (VL), CD4 T cell count, CD4/CD8 ratio at pre-ART, and initial treatment regimen. Baseline WBC count, HGB level, neutrophil/lymphocyte ratio (NLR) were also involved.

\section{Statistical Analysis}

Continuous variables were presented as the medians and interquartile ranges (IQR) due to skewed statistical distributions, while categorical variables were expressed by counts and percentages. The chi-square test was used to evaluate the difference in categorical variables. Descriptive statistics were employed to illustrate the characteristics of the participants and the overall prevalence of thrombocyte abnormalities (including thrombocytopenia and thrombocytosis) at enrollment.

To explore the risk variables independently associated with thrombocytopenia or thrombocytosis, the underlying predictors determined by univariable analysis were further entered into a multivariable logistic regression model. And the final outcomes were displayed as adjusted odds ratios (AOR) with their respective $95 \%$ confidence intervals (CI).

Normalization rates of thrombocytes after ART were evaluated as the number of recovery cases per 100 personyears follow-up (PYFU), and line charts were adopted to describe the restoration trends during the observational period. Incidence density rate of thrombocytopenia and thrombocytosis were also reported as the same way.

Cox proportional hazards models were executed to assess the impact factors on thrombocytosis in HIVsubjects after one year of ART. Characteristics that were considered clinically relevant or that performed a univariate relationship with result were fitted into multivariate analysis to control possible confounders.

Statistical calculations were performed using SPSS software (version 26.0) and GraphPad (version 7.0). All tests were two-tailed, and significance was set at 0.05 .

\section{Results}

\section{Characteristics of the Participants and Prevalence of Thrombocyte}

\section{Abnormalities}

From January, 2013 to August, 2020, we enrolled 6637 HIV/AIDS people in our study. The median age of cohort subjects was 30 years (IQR, 26-37), and the ratio of male to female was $22: 1$. The main transmission route was sexual, which accounted for $92.3 \%$ of cases. In total, $59.7 \%$ of individuals had baseline CD4 counts $<350$ cells/ $\mu \mathrm{L}$. The demographic, immunologic and hematological details are listed in Table 1.

Overall, the prevalence of thrombocytopenia was $2.65 \%(n=176)$, while the prevalence of thrombocytosis was $5.85 \%(n=388)$ prior to initiating ART.

\section{Risk Factors for Thrombocyte} Abnormalities Among ART-Naïve Patients We investigated the independent hazard markers for thrombocytopenia and thrombocytosis in therapy-naïve 
Table I Demographic Data and Clinical Characteristics of the Study Subjects at the Beginning of Antiretroviral Therapy ( $=6637$ )

\begin{tabular}{|c|c|c|c|}
\hline Variables & Thrombocytopenia $(n=\mid 76)$ & Thrombocytosis $(n=388)$ & Normal $(n=6073)$ \\
\hline Age (years) & $34(29,46)$ & $30(25,38)$ & $30(26,37)$ \\
\hline \multicolumn{4}{|l|}{ Sex } \\
\hline Male & $166(94.3)$ & $364(93.8)$ & $5820(95.8)$ \\
\hline Female & $10(5.7)$ & $24(6.2)$ & $253(4.2)$ \\
\hline \multicolumn{4}{|l|}{ Transmission route } \\
\hline Homosexual & II5 (65.3) & $294(75.8)$ & $4893(80.6)$ \\
\hline Heterosexual & $38(21.6)$ & $58(14.9)$ & $733(12.1)$ \\
\hline Other/unknown & $23(13.1)$ & $36(9.3)$ & $447(7.3)$ \\
\hline \multicolumn{4}{|l|}{ WHO clinical stage } \\
\hline I-II & $152(86.4)$ & $347(91.1)$ & $5513(92.2)$ \\
\hline III-IV & $24(13.6)$ & $34(8.9)$ & $469(7.8)$ \\
\hline \multicolumn{4}{|l|}{ BMI $\left(\mathrm{kg} / \mathrm{m}^{2}\right)$} \\
\hline $18.5-24.0$ & $88(66.2)$ & $186(61.4)$ & $3136(65.6)$ \\
\hline$<18.5$ & $19(14.3)$ & $40(13.2)$ & $472(9.9)$ \\
\hline$>24.0$ & $26(19.5)$ & $77(25.4)$ & $1171(24.5)$ \\
\hline \multicolumn{4}{|l|}{$\mathrm{HBsAg}$} \\
\hline Negative & $148(85.5)$ & $363(95.3)$ & $5649(94.7)$ \\
\hline Positive & $25(14.5)$ & $18(4.7)$ & $314(5.3)$ \\
\hline \multicolumn{4}{|l|}{ Anti-HCV } \\
\hline Negative & $166(96.0)$ & $378(99.5)$ & $5833(98.0)$ \\
\hline Positive & $7(4.0)$ & $2(0.5)$ & $119(2.0)$ \\
\hline \multicolumn{4}{|l|}{ Syphilis } \\
\hline Negative & $105(64.4)$ & $205(59.8)$ & $3688(64.9)$ \\
\hline Positive & $58(35.6)$ & $138(40.2)$ & 1992(35.1) \\
\hline \multicolumn{4}{|l|}{ Baseline VL (copies/mL) } \\
\hline$<100,000$ & $88(5 \mid .5)$ & $237(62.7)$ & $4 \mid 43(70.4)$ \\
\hline$\geq 100,000$ & $83(48.5)$ & $|4|(37.3)$ & $1740(29.6)$ \\
\hline \multicolumn{4}{|l|}{ Baseline CD4 count (cells/ $\mu \mathrm{L})$} \\
\hline$<350$ & $144(82.8)$ & $219(56.9)$ & $3595(60.0)$ \\
\hline$\geq 350$ & $30(17.2)$ & $166(43.1)$ & $2397(40.0)$ \\
\hline \multicolumn{4}{|l|}{ Baseline CD4/CD8 ratio } \\
\hline$<0.4$ & $|5|(87.3)$ & $272(71.0)$ & $4238(71.9)$ \\
\hline$\geq 0.4$ & $22(12.7)$ & III(29.0) & $1658(28.1)$ \\
\hline \multicolumn{4}{|l|}{ WBC $\left(\times 10^{9} / \mathrm{L}\right)$} \\
\hline$\geq 4.0$ & $106(60.2)$ & $353(91.0)$ & $5288(87.1)$ \\
\hline$<4.0$ & $70(39.8)$ & $35(9.0)$ & $785(\mid 2.9)$ \\
\hline \multicolumn{4}{|l|}{$\mathrm{HGB}(\mathrm{g} / \mathrm{L})$} \\
\hline$\geq 110$ (Female) or $\geq 120$ (Male) & $119(67.6)$ & $308(79.4)$ & $565 I(93.1)$ \\
\hline$<110($ Female) or $>120($ Male) & $57(32.4)$ & $80(20.6)$ & $422(6.9)$ \\
\hline \multicolumn{4}{|l|}{ NLR } \\
\hline$<2.0$ & $79(46.5)$ & $168(45.8)$ & $3589(61.2)$ \\
\hline $2.0-4.0$ & $60(35.3)$ & $130(35.4)$ & $\mid 791(30.5)$ \\
\hline$>4.0$ & $31(18.2)$ & $69(18.8)$ & $488(8.3)$ \\
\hline
\end{tabular}

Notes: Data are presented as $\mathrm{n}(\%)$, or median (interquartile range). Variable had missing values: $\mathrm{WHO}$ clinical stage $=98$; $\mathrm{BMI}=1422 ; \mathrm{HBV}=120 ; \mathrm{HCV}=132$; Syphilis = 45I; VL = 205; CD4 count $=86 ; \mathrm{CD} 4 / \mathrm{CD} 8$ ratio $=185 ; \mathrm{NLR}=232$.

Abbreviations: WHO, world health organization; BMI, body mass index; HBsAg, hepatitis B surface antigen; Anti-HCV, antibody to hepatitis C virus; VL, viral load; WBC, white blood cell; HGB, haemoglobin; NLR, neutrophil-lymphocyte ratio. 
patients, respectively. Multivariate logistic regression analysis demonstrated that older age (OR: $1.029,95 \% \mathrm{CI}$ : 1.015-1.042, $p<0.001$ ), co-infection with HBV (OR: 2.825, 95\% CI: $1.782-4.480, p<0.001)$, WBC count $<$ $4.0 \times 10^{9} / \mathrm{L}$ (OR: $2.464,95 \%$ CI: $\left.1.717-3.536, p<0.001\right)$, HGB level $<110 \mathrm{~g} / \mathrm{L}$ (female) or $<120 \mathrm{~g} / \mathrm{L}$ (male) (OR: 2.962, 95\% CI: 2.005-4.377, $p<0.001$ ), were connected with increased odds of thrombocytopenia. On the contrary, baseline CD4 count $\geq 350$ cells/uL (OR: $0.527,95 \%$ CI: $0.338-0.821, p=0.005)$ was negatively linked with thrombocytopenia.

As shown in Table 2, pre-ART CD4 count $\geq 350$ cells/ uL (OR: 1.616, 95\% CI: 1.231-2.122, $p=0.001)$, HGB level $<110 \mathrm{~g} / \mathrm{L}$ (female) or $<120 \mathrm{~g} / \mathrm{L}$ (male) (OR: 4.012, 95\% CI: $2.750-5.854, p<0.001)$, NLR grade $2.0-4.0$ (OR: $1.542,95 \%$ CI: $1.172-2.029, p=0.002)$ and NLR $>4.0$ (OR: $2.008,95 \%$ CI: $1.334-3.021, p=0.001$ ) were notably correlated with the presence of thrombocytosis. However, WBC count $<4.0 \times 10^{9} / \mathrm{L}$ (OR: $0.467,95 \%$ CI: $0.291-0.750, p=0.002$ ), contrasted with WBC level $\geq 4.0 \times 10^{9} / \mathrm{L}$, was proved with lower occurrence risk of thrombocytosis.

\section{Normalization Rate of Thrombocyte Abnormalities After ART Introduction}

Normalization rates were reckoned as the number of recovery cases per 100 person-years, and the restoration of thrombocytes was immediately observed after ART started. Longitudinally, the recovery rates of thrombocytopenia (86.6/100 PYFU) and thrombocytosis (54.2/100 PYFU) were the highest in the first year after initiating antiretroviral treatment. The restoration rates of thrombocytopenia/thrombocytosis at different treatment period $(24 \mathrm{~m}, 36 \mathrm{~m}$, and $48 \mathrm{~m})$ were $83.4 / 46.3,66.0 / 35.1$, and 65.3/ 33.9 (Figure 1).

\section{Incidence Rate of Thrombocyte}

\section{Abnormalities After ART Introduction}

After excluding patients who lack follow-up records as well as unusual baseline thrombocyte parameters, the ultimate cohort contained 6074 HIV/AIDS patients (Figure 2). The incidence proportion of new-onset thrombocytopenia and thrombocytosis were $0.5 \%(31 / 6074)$ and $13.4 \%$ (814/ 6074). From the vertical perspective, the incidence rate of thrombocytosis reached the top (7.2/100 PYFU) after one year of ART, which was much higher than thrombocytopenia $(0.25 / 100$ PYFU, $p<0.001)$. The specific incidence rates of thrombocytopenia/thrombocytosis at different ART period $(0,12 \mathrm{~m}, 24 \mathrm{~m}, 36 \mathrm{~m}, 48 \mathrm{~m}, 60 \mathrm{~m}$, $72 \mathrm{~m}$, and $84 \mathrm{~m}$ ) were $2.65 / 5.85,0.25 / 7.2,0.19 / 6.31,0.16 /$ $4.74, \quad 0.16 / 4.55,0.16 / 4.48,0.15 / 4.41$, and $0.15 / 4.39$ (Figure 2).

\section{Risk Factors for New-Onset Thrombocytosis After 12 Months of ART}

Taking into account the performances of platelets oddities throughout the observation period, we further analyzed the perilous elements of new-onset thrombocytosis after 1 year of therapy. So, all the below results precluded thrombocytopenia $(n=13)$ from total cases $(n=5208)$.

On the whole, the number of participants who received zidovudine (AZT)-based regimen was 133 (2.6\%), tenofovir (TDF)-based regimen was 4951 (95.3\%), lopinavir/ ritonavir (LPV/r)-based regimen was $85(1.6 \%)$ and integrase inhibitors (INSTIs) was $26(0.5 \%)$ (Figure $3 \mathrm{~A})$.

As for thrombocytosis, the prevalence before initiation of therapy was 5.85/100 PYFU, whereas after ART, it increased to $7.20 / 100$ PYFU. Of $7.2 \%$ of study subjects with thrombocytosis, $2.7 \%$ were taking AZT-based regimen, $2.7 \%$ were receiving LPV/r-based regimen, and $94.6 \%$ were on TDFbased regimen (Figure 3B). Table 3 displayed the ratio of thrombocythemia in each regimen after 12 months of therapy, and there was no difference among different regimens $(P>0.05)$ (Supplementary Table).

Furthermore, we also assessed other potential burdens via univariate and multivariate Cox proportional hazard models, and the results showed that female (OR: 3.422 , 95\% CI: $2.418-4.843, p<0.001)$ and BMI $>24.0 \mathrm{~kg} / \mathrm{m}^{2}$ (OR: $1.472,95 \%$ CI: $1.145,1.894, p=0.003$, versus normal BMI) had a statistically remarkable relation with the occurrence of thrombocythemia, while the effect of WBC count $<4.0 \times 10^{9} / \mathrm{L}$ (OR: $0.537,95 \%$ CI: 0.349 $0.824, p=0.004$, versus $\mathrm{WBC}$ level $\geq 4.0 \times 10^{9} / \mathrm{L}$ ) was opposite (Table 4).

\section{Discussion}

In our study, the overall prevalence of thrombocytopenia was $2.65 \%$ prior to starting ART, which is inconsistent with the outcomes of previous reports of $4.5 \%-26.0 \%{ }^{3-5}$ The discrepancy may be due to different definitions, races, disease stages, and the benefits of implementing of "treated all" strategy in recent years.

Cytopenia often affects all lineages of blood cells including anemia, leukopenia as well as 


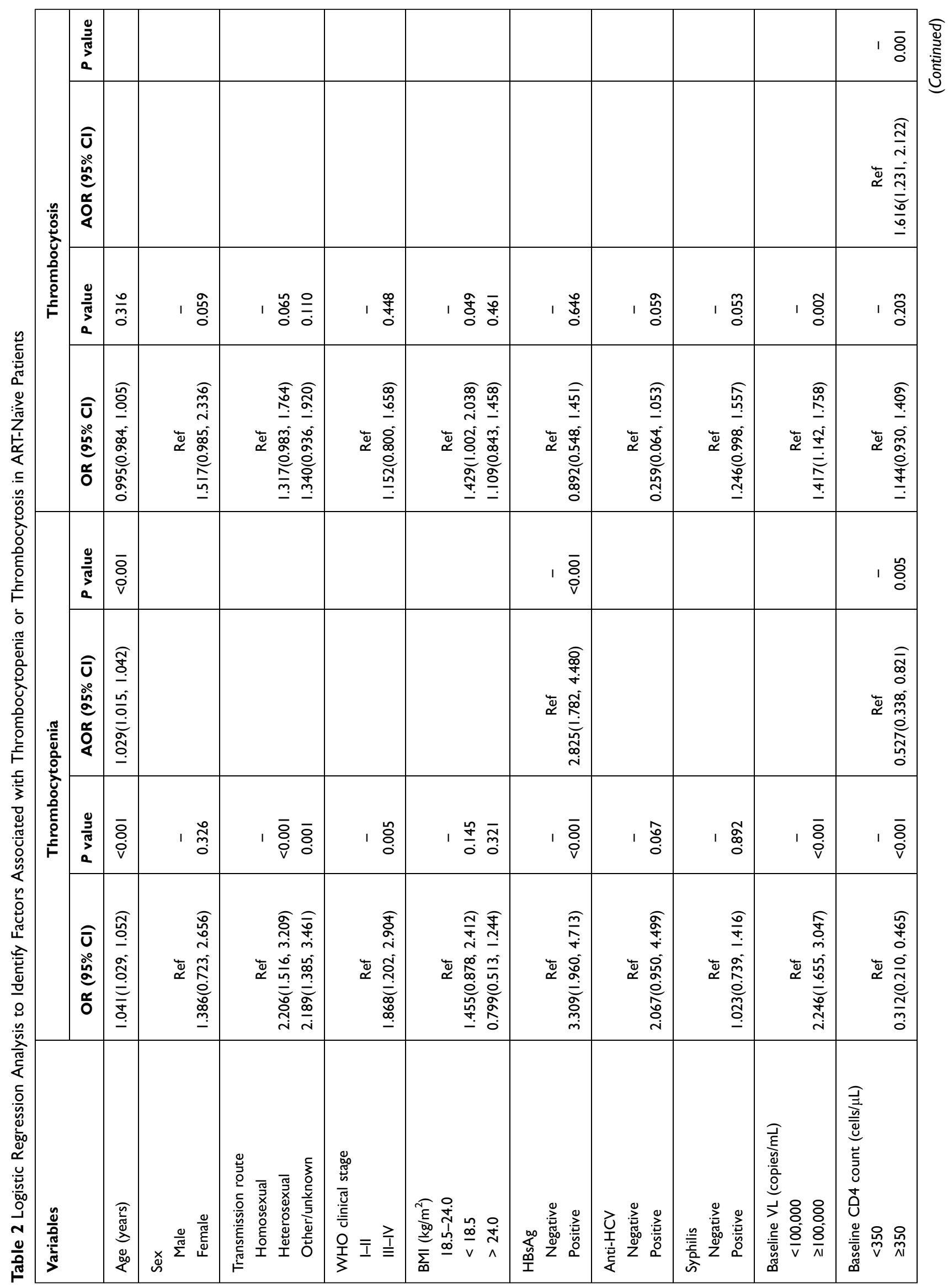




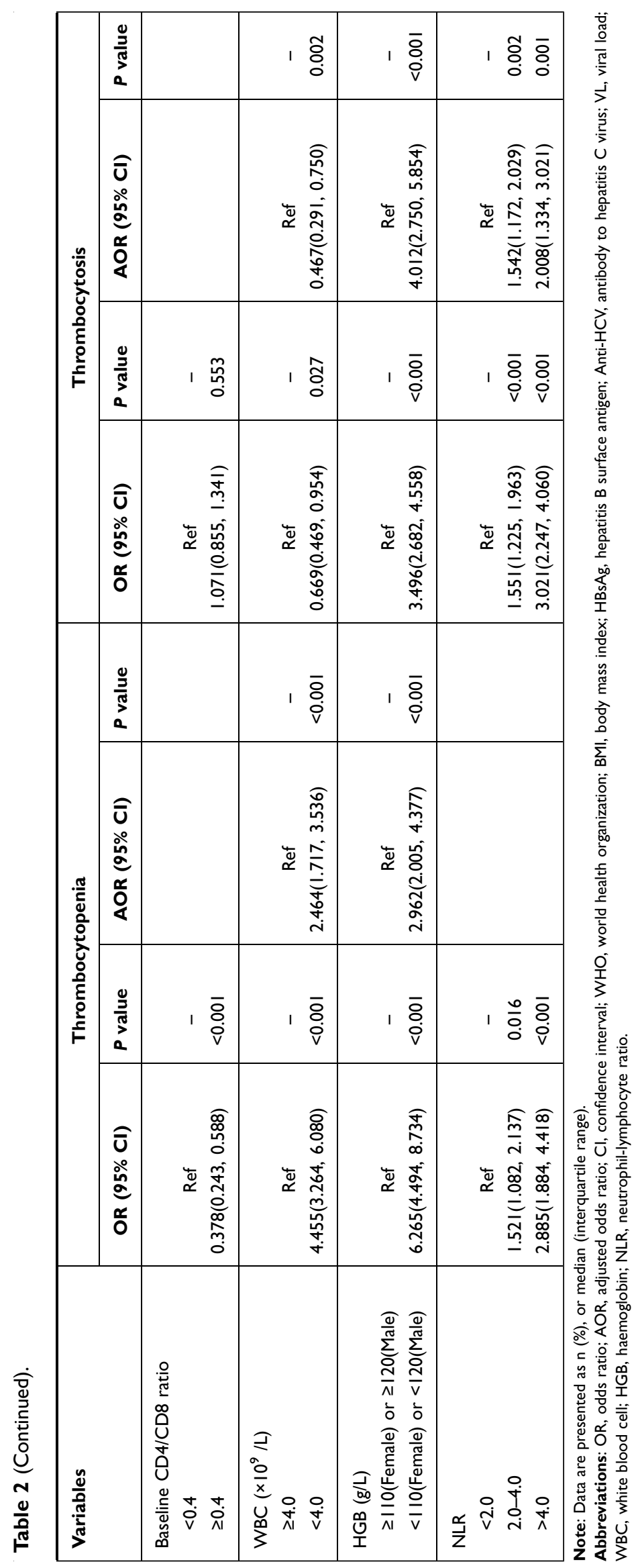




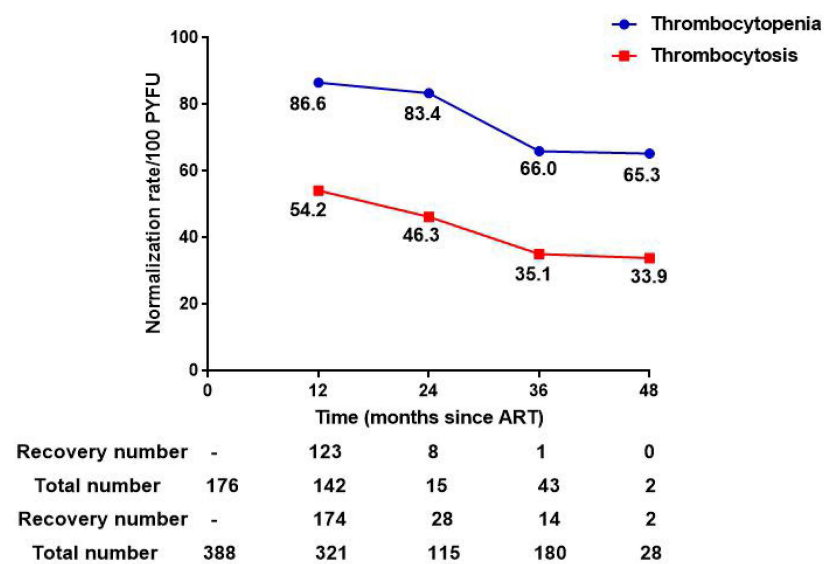

Figure I Recovery rate of thrombocyte abnormalities at different treatment duration. Recovery rate of thrombocytopenia and thrombocytosis after 12, 24, 36 , and 48 months of antiretroviral therapy (blue: thrombocytopenia; red: thrombocytosis).
A

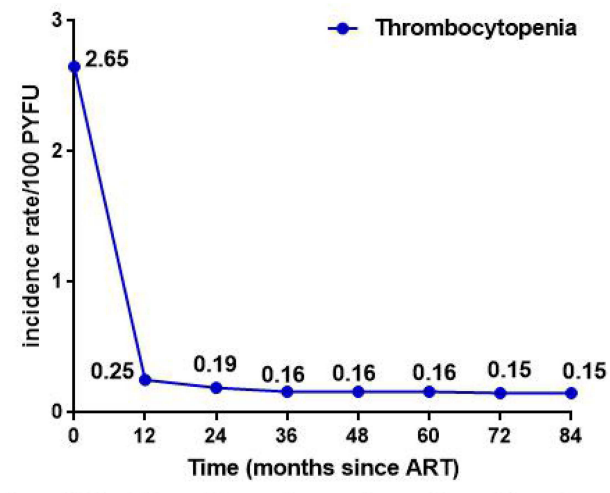

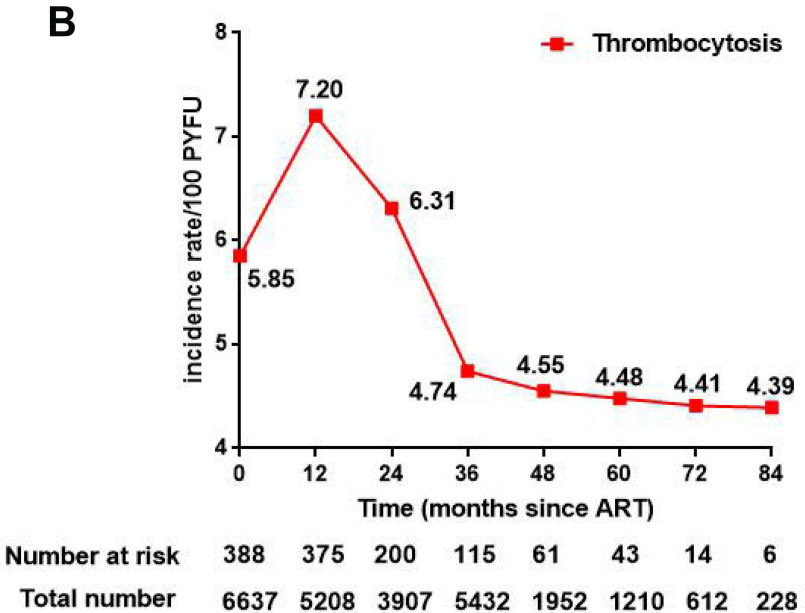

Figure 2 Incidence of new-onset thrombocyte abnormalities at different treatment duration. (A) Rate of new-onset thrombocytopenia after 12, 24, 36, 48, 60, 72, and 84 months of antiretroviral therapy. (B) Rate of new-onset thrombocytosis after 12 , $24,36,48,60,72$, and 84 months of antiretroviral therapy.

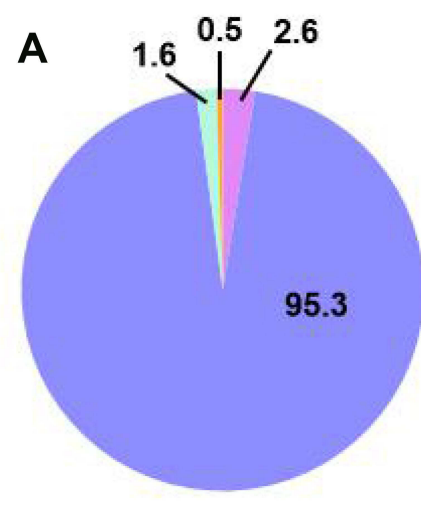

AZT based

TDF based

LPV/r based

INSTIS

\section{Total $=\mathbf{5 1 9 5}$}

B

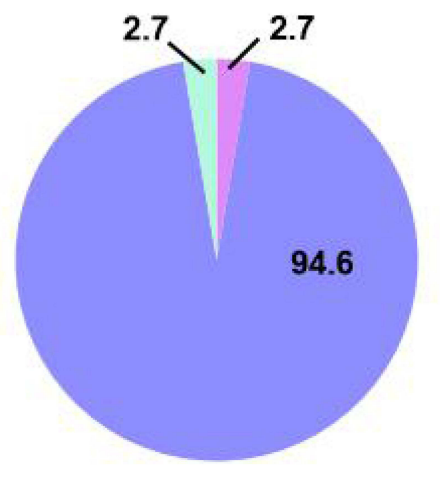

Total $=375$
AZT based

TDF based

LPV/r based

Figure 3 The proportion of different antiretroviral treatment regimens among HIVinfected patients. (A) The proportion of different antiretroviral treatment regimens among total subjects $(n=5 \mid 95)$. (B) The proportion of different antiretroviral treatment regimens in subjects with thrombocytosis $(n=375)$.

Abbreviations: AZT, zidovudine; TDF, tenofovir; LPV/r, lopinavir/ritonavir; INSTIs, integrase inhibitors.

thrombocytopenia, and are the most common complications of treatment-naïve patients. ${ }^{6,7}$ Higher viral loads, lower baseline CD4 levels, and advanced disease status

Table 3 The Ratio of Thrombocytosis in Each Regimen After 12 Months of Therapy

\begin{tabular}{|l|c|c|}
\hline \multirow{2}{*}{ ART Regimen } & \multicolumn{2}{|c|}{ Total Number } \\
\cline { 2 - 3 } & Normal & Thrombocytosis \\
\hline TDF based & $4596(92.83 \%)$ & $355(7.17 \%)$ \\
AZT based & $123(92.48 \%)$ & $10(7.52 \%)$ \\
LPV/r based & $75(88.24 \%)$ & $10(11.76 \%)$ \\
INSTls & $26(100 \%)$ & $0(0 \%)$ \\
\hline
\end{tabular}

Abbreviations: ART, antiretroviral therapy; TDF, tenofovir disoproxil fumarate; AZT, zidovudine; LPV/r, lopinavir/ritonavir; INSTIs, integrase inhibitors. 
Table 4 Cox Proportional Hazard Regression Analysis to Identify Risk Factors Related to Thrombocytosis After 12 Months of Treatment

\begin{tabular}{|c|c|c|c|c|c|c|c|c|}
\hline \multirow[t]{2}{*}{ Factors } & \multicolumn{2}{|c|}{$\begin{array}{c}\text { Thrombocytosis } \\
\qquad(n=375)\end{array}$} & \multicolumn{2}{|c|}{$\begin{array}{l}\text { Normal } \\
(n=4820)\end{array}$} & \multicolumn{2}{|c|}{ Univariate Analysis } & \multicolumn{2}{|c|}{ Multivariate Analysis } \\
\hline & $\mathbf{N}$ & $\%$ & $\mathbf{N}$ & $\%$ & HR (95\% Cl) & $P$ value & HR (95\% Cl) & $P$ value \\
\hline \multicolumn{9}{|l|}{ Age (years) } \\
\hline$<30$ & 195 & 52 & 2433 & 50.5 & Ref & - & & \\
\hline$\geq 30$ & 180 & 48 & 2387 & 49.5 & $0.897(0.733,1.099)$ & 0.295 & & \\
\hline \multicolumn{9}{|l|}{ Sex } \\
\hline Male & 333 & 88.8 & 4654 & 96.6 & Ref & - & Ref & - \\
\hline Female & 42 & 11.2 & 166 & 3.4 & $2.746(1.992,3.786)$ & $<0.001$ & $3.422(2.418,4.843)$ & $<0.001$ \\
\hline \multicolumn{9}{|l|}{ Transmission route } \\
\hline Homosexual & 282 & 75.2 & 3908 & $8 I .1$ & Ref & - & & \\
\hline Heterosexual & 66 & 17.6 & 551 & $1 \mathrm{I} .4$ & $1.640(1.254,2.143)$ & $<0.001$ & & \\
\hline Other/unknown & 27 & 7.2 & 361 & 7.5 & $1.043(0.702,1.547)$ & 0.836 & & \\
\hline \multicolumn{9}{|l|}{ WHO clinical stage } \\
\hline I-II & 344 & 91.7 & 4352 & 90.3 & Ref & - & & \\
\hline III-IV & 23 & 6.1 & 388 & 8.0 & $0.674(0.442,1.029)$ & 0.067 & & \\
\hline \multicolumn{9}{|l|}{ BMI $\left(\mathrm{kg} / \mathrm{m}^{2}\right)$} \\
\hline $18.5-24.0$ & 173 & 46.1 & 2503 & 51.9 & Ref & - & Ref & - \\
\hline$<18.5$ & 23 & 6.1 & 354 & 7.3 & $0.995(0.618,1.475)$ & 0.835 & $0.984(0.636, I .524)$ & 0.943 \\
\hline$>24.0$ & 96 & 25.6 & 887 & 18.4 & $1.437(1.119,1.844)$ & 0.004 & I.472(I.I45, I.894) & 0.003 \\
\hline \multicolumn{9}{|l|}{$\mathrm{HBsAg}$} \\
\hline Negative & 352 & 93.9 & 4494 & 93.2 & Ref & - & & \\
\hline Positive & 17 & 4.5 & 258 & 5.4 & $0.785(0.482$, I.277) & 0.329 & & \\
\hline \multicolumn{9}{|l|}{ Anti-HCV } \\
\hline Negative & 367 & 97.9 & 4639 & 96.2 & Ref & - & & \\
\hline Positive & 4 & 1.1 & 100 & 2.1 & $0.462(0.173,1.238)$ & 0.125 & & \\
\hline \multicolumn{9}{|l|}{ Syphilis } \\
\hline Negative & 241 & 64.3 & 3008 & 62.4 & Ref & - & & \\
\hline Positive & 113 & 30.1 & 1617 & 33.5 & $0.847(0.678,1.059)$ & 0.146 & & \\
\hline \multicolumn{9}{|l|}{ Baseline VL (copies/mL) } \\
\hline$<100,000$ & 248 & 66.1 & 3312 & 68.7 & Ref & - & & \\
\hline$\geq 100,000$ & 119 & 31.7 & $136 \mid$ & 28.2 & $1.097(0.882,1.366)$ & 0.405 & & \\
\hline \multicolumn{9}{|l|}{ Baseline CD4 count $\left(\times 10^{9} / \mathrm{L}\right)$} \\
\hline$<350$ & 205 & 54.7 & 2862 & 59.4 & Ref & - & & \\
\hline$\geq 350$ & 164 & 43.7 & 1900 & 39.4 & $1.214(0.989,1.491)$ & 0.064 & & \\
\hline \multicolumn{9}{|l|}{ Baseline CD4/CD8 ratio } \\
\hline$<0.4$ & 267 & 71.2 & 3329 & 69.1 & Ref & - & & \\
\hline$\geq 0.4$ & 95 & 25.3 & $135 \mid$ & 28.0 & $0.943(0.746,1.192)$ & 0.626 & & \\
\hline \multicolumn{9}{|l|}{ CD4 count at I year of ART $\left(\times 10^{9} / \mathrm{L}\right)$} \\
\hline$<350$ & 73 & 19.5 & 1014 & 21.0 & Ref & - & & \\
\hline$\geq 350$ & 226 & 60.3 & 2781 & 57.7 & I.150(0.884, I.496) & 0.297 & & \\
\hline \multicolumn{9}{|l|}{ WBC $\left(\times 10^{9} / \mathrm{L}\right)$} \\
\hline$\geq 4.0$ & 342 & 91.2 & 4196 & 87.1 & Ref & - & Ref & - \\
\hline$<4.0$ & 33 & 8.8 & 624 & 12.9 & $0.634(0.443,0.906)$ & 0.012 & $0.537(0.349,0.824)$ & 0.004 \\
\hline
\end{tabular}

(Continued) 
Table 4 (Continued).

\begin{tabular}{|c|c|c|c|c|c|c|c|c|}
\hline \multirow[t]{2}{*}{ Factors } & \multicolumn{2}{|c|}{$\begin{array}{l}\text { Thrombocytosis } \\
\qquad(n=375)\end{array}$} & \multicolumn{2}{|c|}{$\begin{array}{l}\text { Normal } \\
(n=4820)\end{array}$} & \multicolumn{2}{|c|}{ Univariate Analysis } & \multicolumn{2}{|c|}{ Multivariate Analysis } \\
\hline & $\mathbf{N}$ & $\%$ & $\mathbf{N}$ & $\%$ & HR (95\% Cl) & $P$ value & HR (95\% Cl) & $P$ value \\
\hline \multicolumn{9}{|l|}{ HGB $(g / L)$} \\
\hline$\geq \mid$ I 0 (Female) or $\geq 120$ (Male) & 348 & 92.8 & 4506 & 93.5 & Ref & - & & \\
\hline$<1$ I0(Female) or >120(Male) & 27 & 7.2 & 314 & 6.5 & $1.032(0.697,1.526)$ & 0.876 & & \\
\hline \multicolumn{9}{|l|}{ NLR } \\
\hline$<2.0$ & 237 & 63.2 & 2867 & 59.5 & Ref & - & & \\
\hline $2.0-4.0$ & 101 & 26.9 & 1460 & 30.3 & $0.863(0.682,1.090)$ & 0.216 & & \\
\hline$>4.0$ & 31 & 8.3 & 369 & 7.7 & $1.060(0.733,1.534)$ & 0.755 & & \\
\hline
\end{tabular}

Notes: Data are presented as $\mathrm{n}(\%)$, or median (interquartile range). Variable had missing values: $\mathrm{WHO}$ clinical stage = 88; $\mathrm{BMI}=1 \mathrm{I}$ (59; $\mathrm{HBV}=74$; $\mathrm{HCV}=85 ;$ Syphilis = 2I6; $V L=155 ;$ CD4 count $=64 ; C D 4 / C D 8$ ratio $=153 ;$ CD4 count at I year of ART $=1101 ; \mathrm{NLR}=130$.

Abbreviations: $\mathrm{HR}$, hazard ratio; $\mathrm{Cl}$, confidence interval; WHO, world health organization; $\mathrm{BMI}$, body mass index; $\mathrm{HBs} \mathrm{Ag}$, hepatitis $\mathrm{B}$ surface antigen; $\mathrm{Anti}-\mathrm{HCV}$, antibody to hepatitis C virus; VL, viral load; WBC, white blood cell; HGB, haemoglobin; NLR, neutrophil-lymphocyte ratio.

are the driving forces for cytopenia among HIV/AIDS individuals. ${ }^{3,8,9}$ Just as our study observed, patients with lower WBC, HGB and CD4 counts had an increased occurrence of thrombocytopenia.

Moreover, we also found that thrombocytopenia was remarkably associated with older age and $\mathrm{HBV}$-infected. Populations of our cohort ranged from 18 to 83 years with a median age of 30 years (IQR: 26-37), which prompted the fact that young people with sexually active were vulnerable to HIV. ${ }^{10}$ Besides, it also may be due to a higher prevalence of myelodysplasia in older persons. ${ }^{11}$ HIV infection promoted hepatitis B activity, while liver impairments damaged thrombopoietin production, they worked together to accelerate the thrombocytopenia. ${ }^{12,13}$

Antiretroviral therapy can effectively recover the amounts of platelets. ${ }^{14,15}$ Considering the myelosuppressive effects of AZT, ${ }^{16,17}$ Ditan Hospital has gradually adopted $\mathrm{TDF}+3 \mathrm{TC}+\mathrm{EFV}$ as the preferred regimen for HIV-infected patients since 2009. Nowadays, AZTrelated thrombocytopenia has been relatively rare.

Compared with thrombocytopenia, thrombocytosis was often overlooked and the relevant data was limited. In our study, its prevalence was $5.85 \%$ among treatment-naïve patients. It can be divided as two types: primary/secondary thrombocythemia. ${ }^{18}$ The latter is the most common in nowadays whose causes usually include acute/chronic infection, inflammation, hemorrhage/iron deficiency, drugs, and so on. ${ }^{19,20}$

The causes of thrombocytosis in HIV infection are complex. HIV virus itself, ${ }^{21}$ immune activation factors (such as interleukins-1, IL-6, and tumor necrosis factor), anemia, protease inhibitors and others all contribute to its occurrence. IL-6 has thrombopoietic-like activity, ${ }^{22}$ can cause a rise in thrombopoietin and the development of reactive thrombocytosis, ${ }^{23}$ while erythropoietin has a structural similarity to thrombopoietin and could directly stimulate thrombopoietin receptors. ${ }^{24}$ Moreover, protease inhibitors play a critical role in platelets storage by improving platelet survival time and reduce platelet aggregation. ${ }^{25,26}$ With the therapy prolongs, HIV viremia is suppressed, the degree of immune activation is decreased, and anemia is rectified. It seems the reason why the incidence rate of thrombocytosis is higher within short-time ART, and lower after long-time ART.

In agreement with the above description, our consequences showed that patients with higher baseline CD4 counts, anemia, and elevated NLR were more susceptible to thrombocytosis. NLR was an indication of systemic inflammation and interrelated with all-cause mortality among HIV-infected people. ${ }^{27,28}$

Our data also reflected that anti-retroviral treatment had dual effects on thrombocytosis. ${ }^{29-31}$ On the one hand, it can partially recover the quantity of PLTs; on the other hand, it promotes the appearance of thrombocytosis. Additionally, females and overweight were related to thrombocytosis in the process of ART. The possible explanations were anemia (such as menorrhagia, iron deficiency) and overnutrition. ${ }^{32}$ Megakaryocyte proliferation was the reason for PLT count increased in iron deficiency anemia. $^{22,33}$

HIV-1 infection increased the level of platelets activation. ${ }^{34} \mathrm{~A}$ variety of cytokines including IL-1, IL-6, 
TNF- $\alpha$, TGF- $\beta$, and sCD14 were released by activated platelets promoted the occurrence of systemic inflammation, ${ }^{31,35}$ then triggered multiple NAD (cardiovascular events, neurocognitive disorders, renal fibrosis). ${ }^{34,36}$ Thrombocytosis further accelerated this process, and platelets activation still persisted despite successful ART. ${ }^{34}$

Objectively speaking, thrombocytopenia, which often causes critical situations that need to take medical action immediately (such as gastrointestinal hemorrhage, cerebral hemorrhage), has attracted deep attention. From the classification of WHO clinical stages to the formulation of clinical diagnosis and treatment strategies, ${ }^{37}$ thrombocytopenia has always been an important consideration. While, the effects of thrombocytosis tend to be ignored in the clinical practice despite the consensus that it is an abnormal indicator. To make matters worse that PLT play a part in certain chronic disease (such as ischemic thrombosis and cardiovascular events ${ }^{34}$ ) which will bring patients with fatal trouble.

Our results showed that the incidence of thrombocytosis was much higher than that of thrombocytopenia, whether in ART-naïve patients or during ART. Simultaneously, the recovery rate of thrombocytosis by antiviral therapy was far less than thrombocytopenia. Therefore, while paying attention to thrombocytopenia, we should be highly vigilant about the thrombocytosis, and multidisciplinary collaboration is needed if necessary. It was reported that as classic antiplatelet drugs, clopidogrel and low-dose aspirin also have anti-inflammatory and anti-activation effects. ${ }^{38,39}$ The clinical applications of them in HIV infection and pathogenesis remain further study.

This study has some limitations. Firstly, based on the inherent weakness of the retrospective study. Secondly, observational research restricts the discussion of mechanisms. Nevertheless, this large cohort investigation still likely reflects the actual circumstances of thrombocyte abnormalities of Chinese HIV-infected adults.

\section{Conclusion}

In the medical practice, while paying attention to thrombocytopenia, clinicians should be highly vigilant about the thrombocytosis of HIV/AIDS patients, and related treatment strategies need to be further studied.

\section{Acknowledgments}

The authors acknowledge the work of HIV healthcare providers for their diagnosis, nursing, and treatment of HIV/AIDS patients in Ditan Hospital.

\section{Author Contributions}

All authors made a significant contribution to the work reported, whether that is in the conception, study design, execution, acquisition of data, analysis and interpretation; and took part in drafting, revising or critically reviewing the article. Furthermore, all authors gave final approval for the version to be published; have agreed on the journal to which the article has been submitted.

\section{Funding}

This work was supported by the Beijing Municipal Administration of Hospitals' Ascent Plan (No. DFL20191802) and Beijing Municipal Administration of Hospitals Clinical Medicine Development of Special Funding Support (No. ZYLX202126).

\section{Disclosure}

All authors declared that there are no conflicts of interest.

\section{References}

1. George JN. Platelets. Lancet. 2000;355(9214):1531-1539. doi:10.1016/s0140-6736(00)02175-9

2. Borges AH, Lundgren JD, Ridolfo A, et al. Thrombocytopenia is associated with an increased risk of cancer during treated HIV disease. AIDS. 2014;28(17):2565-2571. doi:10.1097/qad.0000000000000433

3. Shen Y, Wang J, Wang Z, et al. A cross-sectional study of leukopenia and thrombocytopenia among Chinese adults with newly diagnosed HIV/AIDS. Biosci Trends. 2015;9(2):91-96. doi:10.5582/ bst.2015.01024

4. Fan H-W, Guo F-P, Li Y-J, et al. Prevalence of thrombocytopenia among Chinese adult antiretroviral-naïve HIV-positive patients. Chin Med J. 2015;128(4):459-464. doi:10.4103/0366-6999.151078

5. Ambler KLS, Vickars LM, Leger CS, et al. Clinical features, treatment, and outcome of HIV-associated immune thrombocytopenia in the HAART era. Adv Hematol. 2012;2012:910954. doi:10.1155/2012/ 910954

6. Bello JL, Burgaleta C, Magallon M, et al. Hematological abnormalities in hemophilic patients with human immunodeficiency virus infection. Am J Hematol. 1990;33(4):230-233. doi:10.1002/ ajh. 2830330403

7. Erhabor O, Ejele OA, Nwauche CA, et al. Some haematological parameters in human immunodeficiency virus (HIV) infected Africans: the Nigerian perspective. Niger J Med. 2005;14(1):33-38. doi:10.4314/njm.v14i1.37132

8. Kyeyune R, Saathoff E, Ezeamama AE, et al. Prevalence and correlates of cytopenias in HIV-infected adults initiating highly active antiretroviral therapy in Uganda. BMC Infect Dis. 2014;14:496. doi:10.1186/1471-2334-14-496

9. Fan L, Li C, Zhao H. Prevalence and risk factors of cytopenia in HIV-infected patients before and after the initiation of HAART. Biomed Res Int. 2020;2020:3132589. doi:10.1155/2020/3132589

10. Nka AD, Sosso SM, Fokam J, et al. Thrombocytopenia according to antiretroviral drug combinations, viremia and CD4 lymphocytes among HIV-infected patients in Cameroon: a snapshot from the City of Yaoundé. BMC Res Notes. 2019;12(1):632. doi:10.1186/ s13104-019-4664-7 
11. Lai SW, Huang CY, Lai HC, et al. Thrombocytopenia and its related factors: a hospital-based, cross-sectional study. Ann Acad Med Singapore. 2010;39(1):9-12.

12. Wang X, Jiang W, Li F, et al. Abnormal platelet kinetics are detected before the occurrence of thrombocytopaenia in HBV-related liver disease. Liver Int. 2014;34(4):535-543. doi:10.1111/liv.12309

13. Rios R, Sangro B, Herrero I, et al. The role of thrombopoietin in the thrombocytopenia of patients with liver cirrhosis. $\mathrm{Am}$ $J$ Gastroenterol. 2005;100(6):1311-1316. doi:10.1111/j.15720241.2005.41543.x

14. Choi SY, Kim I, Kim NJ, et al. Hematological manifestations of human immunodeficiency virus infection and the effect of highly active anti-retroviral therapy on cytopenia. Korean $\mathrm{J}$ Hematol. 2011;46(4):253-257. doi:10.5045/kjh.2011.46.4.253

15. Deressa T, Damtie D, Workineh M, et al. Anemia and thrombocytopenia in the cohort of HIV-infected adults in northwest Ethiopia: a facility-based cross-sectional study. EJIFCC. 2018;29(1):36-47.

16. Woldeamanuel GG, Wondimu DH. Prevalence of thrombocytopenia before and after initiation of HAART among HIV infected patients at black lion specialized hospital, Addis Ababa, Ethiopia: a cross sectional study. BMC Hematol. 2018;18:9. doi:10.1186/s12878-0180103-6

17. Cretton EM, Xie MY, Bevan RJ, et al. Catabolism of 3'-azido-3'deoxythymidine in hepatocytes and liver microsomes, with evidence of formation of 3'-amino-3'-deoxythymidine, a highly toxic catabolite for human bone marrow cells. Mol Pharmacol. 1991;39(2):258-266.

18. Schafer AI. Thrombocytosis. JAMA. 2015;314(11):1171-1172. doi:10.1001/jama.2015.8515

19. McMullin MF. Diagnostic workflow for hereditary erythrocytosis and thrombocytosis. Hematol Am Soc Hematol Edu Program. 2019;2019 (1):391-396. doi:10.1182/hematology.2019000047

20. Rose SR, Petersen NJ, Gardner TJ, et al. Etiology of thrombocytosis in a general medicine population: analysis of 801 cases with emphasis on infectious causes. J Clin Med Res. 2012;4(6):415-423. doi: $10.4021 /$ jocmr $1125 \mathrm{w}$

21. Ellaurie M. Thrombocytosis in pediatric HIV infection. Clin Pediatr. 2004;43(7):627-629. doi:10.1177/000992280404300707

22. Schafer AI. Thrombocytosis. $N$ Engl J Med. 2004;350 (12):1211-1219. doi:10.1056/NEJMra035363

23. Gauldie J, Richards C, Harnish D, et al. Interferon B2/B-cell stimulatory factor type 2 shares identity with monocyte-derived hepatocyte-stimulating factor and regulates the major acute-phase protein response in liver cells. Proc Natl Acad Sci U S A. 1987;84 (20):7251-7255. doi:10.1073/pnas.84.20.7251

24. Bilic E, Bilic E. Amino acid sequence homology of throm-bopoietin and erythropoietin may explain thrombocytosis in children with iron deficiency anemia. J Pediatr Hematol Oncol. 2003;25(8):675-676. doi:10.1097/00043426-200308000-00023

25. Dubé MP, Sprecher D, Henry WK, et al. Preliminary guidelines for the evaluation and management of dyslipidemia in adults infected with human immunodeficiency virus and receiving antiretroviral therapy: recommendations of the Adult AIDS Clinical Trial Group Cardiovascular Disease Focus Group. Clin Infect Dis. 2000;31 (5):1216-1224. doi:10.1086/317429

Infection and Drug Resistance

\section{Publish your work in this journal}

Infection and Drug Resistance is an international, peer-reviewed openaccess journal that focuses on the optimal treatment of infection (bacterial, fungal and viral) and the development and institution of preventive strategies to minimize the development and spread of resistance. The journal is specifically concerned with the epidemiology of
26. Savona S, Nardi MA, Lennette ET, et al. Thrombocytopenic purpura in narcotics addicts. Ann Intern Med. 1985;102(6):737-741. doi:10.7326/0003-4819-102-6-737

27. Raffetti E, Donato F, Casari S, et al. Systemic inflammation-based scores and mortality for all causes in HIV-infected patients: a MASTER cohort study. BMC Infect Dis. 2017;17(1):193. doi:10.1186/s12879-017-2280-5

28. Takenaka Y, Oya R, Kitamiura $T$, et al. Prognostic role of neutrophil-to-lymphocyte ratio in head and neck cancer: a meta-analysis. Head Neck. 2018;40(3):647-655. doi:10.1002/ hed.24986

29. Taylor KA, Smyth E, Rauzi F, et al. Pharmacological impact of antiretroviral therapy on platelet function to investigate human immunodeficiency virus-associated cardiovascular risk. Br J Pharmacol. 2019;176(7):879-889. doi:10.1111/bph.14589

30. Loelius SG, Lannan KL, Blumberg N, et al. The HIV protease inhibitor, ritonavir, dysregulates human platelet function in vitro. Thromb Res. 2018;169:96-104. doi:10.1016/j.thromres.2018.07.003

31. Laurence J, Elhadad S, Gostynska S, et al. HIV protease inhibitor ritonavir induces renal fibrosis and dysfunction: role of plateletderived TGF- $\beta 1$ and intervention via antioxidant pathways. AIDS. 2020;34(7):989-1000. doi:10.1097/qad.0000000000002516

32. Dai G, Xiao J, Gao G, et al. Anemia in combined antiretroviral treatment-naive HIV-infected patients in China: a retrospective study of prevalence, risk factors, and mortality. Biosci Trends. 2017;10(6):445-453. doi:10.5582/bst.2016.01165

33. Evstatiev R, Bukaty A, Jimenez K, et al. Iron deficiency alters megakaryopoiesis and platelet phenotype independent of thrombopoietin. Am J Hematol. 2014;89(5):524-529. doi:10.1002/ ajh. 23682

34. Mesquita EC, Hottz ED, Amancio RT, et al. Persistent platelet activation and apoptosis in virologically suppressed HIV-infected individuals. Sci Rep. 2018;8(1):14999. doi:10.1038/s41598-01833403-0

35. Neuhaus J, Jacobs, Jr DR, Baker JV, et al. Markers of inflammation, coagulation, and renal function are elevated in adults with HIV infection. J Infect Dis. 2010;201(12):1788-1795. doi:10.1086/652749

36. Gleissner CA, Hundelshausen P, Ley K. Platelet chemokines in vascular disease. Arteriosclerosis, thrombosis, and vascular biology. Arteriosclerosis, Thrombosis, Vasc Biol. 2008;28(11):1920-1927. doi:10.1161/atvbaha.108.169417

37. World Health Organization. Consolidated Guidelines on the Use of Antiretroviral Drugs for Treating and Preventing HIV Infection: Recommendations for a Public Health Approach. World Health Organization; 2013.

38. O'Brien MP, Zafar MU, Rodriguez JC, et al. Targeting thrombogenicity and inflammation in chronic HIV infection. Sci Adv. 2019;5(6): eaav5463. doi:10.1126/sciadv.aav5463

39. O'Brien M, Montenont E, Hu L, et al. Aspirin attenuates platelet activation and immune activation in HIV-1-infected subjects on antiretroviral therapy: a pilot study. J Acquir Immune Defic Syndr. 2013;63(3):280-288. doi:10.1097/QAI.0b013e31828a292c antibiotic resistance and the mechanisms of resistance development and diffusion in both hospitals and the community. The manuscript management system is completely online and includes a very quick and fair peerreview system, which is all easy to use. Visit http://www.dovepress.com/ testimonials.php to read real quotes from published authors. 